\title{
The effect of ultra-high pressure and heat on the allergenicity and structural properties of bovine serum albumin.
}

\author{
Yepei Zhu, Wei Wang*, Tianhao Chen, Guanghong Zhou
}

National Center of Meat Quality and Safety Control, Key Laboratory of Animal Products Processing, Ministry of Agriculture, Synergetic Innovation Center of Food Safety and Nutrition, Nanjing Agricultural University, PR China

\begin{abstract}
The objective of this study is to investigate the impact of Ultra-High Pressure (UHP) combined with moderate heat treatment on the allergenic properties of Bovine Serum Albumin (BSA). The effects of high pressure treatment at 100-500 MPa on allergenicity and structural properties of BSA were investigated. This study was performed using Competitive Indirect-Enzyme Linked Immunosorbent Analysis (CI-ELISA) to get the allergenicity change of BSA and the spectroscopy technology to get the structural properties change. At $500 \mathrm{MPa}$ and $55^{\circ} \mathrm{C}$, the inhibition of IgE decreased and reached a maximum of $17.5 \%$ relative to untreated BSA. At $100-500 \mathrm{MPa}$ and $25-40^{\circ} \mathrm{C}$, the free Sulfhydryl (SH) content, relative surface hydrophobicity $\left(\mathrm{H}_{0}\right)$ and the fluorescence intensity of BSA significantly $(\mathrm{P}<0.05)$ increased at first and then decreased with increasing pressure. A pressure of $100 \mathrm{MPa}$ gave the maximum increase, but using $55^{\circ} \mathrm{C}$ resulted in a significantly decrease in $\mathrm{SH}, \mathrm{H}_{0}$ and fluorescence intensity. This might be due to protein refolding and subsequent aggregation or association. A significant change in the secondary structure was also detected at higher temperatures. UHP combined with higher temperature treatments resulted in a significant decrease in the number of $\alpha$-helices and a significant increase in $\beta$-sheets, $\beta$-turns and random coils. These interactions and the secondary results provide direct explanation for the UHP- and heat-induced modification of BSA. This could alter the allergenicity of BSA and enhance the security of beef, milk and beef products.
\end{abstract}

Keywords: Ultra-high pressure (UHP), Heat treatment, Bovine serum albumin (BSA), Allergenicity, Structural properties.

Accepted on May 22, 2017

\section{Introduction}

Food allergies have become increasingly widespread in recent years and are an important public health concern [1]. Approximately $1-2 \%$ of infants, $8 \%$ of children, and many adults have some types of food allergy [2,3]. Common examples include wheat, milk, eggs and meat. While avoiding these foods is the most obvious and simple approach to combatting food allergies, these foods are often nutritious and indispensable for normal growth and development. Strict avoidance of food allergens can thus trigger other health issues [4].

Meat and meat products are particularly important foods because of their high nutritional value and functional properties. Although relatively rare compared to common food allergies (e.g., dairy, shrimp, peanuts, etc.), allergies to meat can be very serious and life-threatening [1]. Porcine Serum Albumin (PSA) is one of the man allergens in pork. Many researchers discovered the IgG binding ability of PSA can be reduced to $29 \%$ by autoclave treatment at 121 for $30 \mathrm{~min}[5,6]$. Bovine Serum Albumin (BSA) is one of the most important allergens in bovine meat as well as in milk. However, the researches about the BSA allergenicity reduce were rare. Restani et al. [7] suggested that serum albumin antigenicity was only partially correlated with its native three-dimensional structure [8]. Beef allergies often have high cross-reactivity with other meat allergies, and reducing the allergenicity of BSA is very important for beef and cow's milk [1].

Food technology aims to reduce or eliminate allergenicity by either irreversible removal of allergens or modifying the allergen structure in such a way that the allergenic epitopes are no longer recognized by the immune system. For example, Besler et al. [9] have eliminated allergenic elements from cow's milk by combining enzymatic and heat treatments with ultra-filtration. In addition, Nishio et al. [10] removed the 16 $\mathrm{kDa}$ allergenic components in rice by enzymatic treatment. These hypoallergenic milk and rice products are now supplied to allergic patients. Although enzymatic treatments have generally been used to eliminate food allergenicity, such treatments can also degrade flavor and taste. Moreover, enzymatic treatment of foods with high protein content, e.g. meat, is impractical [1]. 
Recently, many studies have used Ultra-High Pressure (UHP) to reduce food allergens. This is a non-thermal technology and thus only has a minor influence on small molecule nutrients (amino acids, small molecular components, vitamins, etc.) However, UHP does have significant impact on the secondary, tertiary and quaternary structure of treated protein and thus can markedly alter antigenic properties by modulating noncovalent bonds, hydrogen bonds and hydrophilic interactions $[11,12]$. Johnson et al. [13] stated that UHP changed the secondary structure of the apple allergens Mal d 1 and Mal d 3 and decreased the immunoreactivity of Mal d 3. Hajos et al. [14] reported that the high pressure caused conformational changes in pork proteins and altered some epitopes. This group found that $600 \mathrm{MPa}$ reduced the $\operatorname{IgE}$ immunoreactivity of the proteins in fermented sausage. Therefore, the application of UHP in terms of reducing BSA allergenicity presented great potential.

To the best of our knowledge, less report is conducted to characterize the impact of UHP and moderate heat treatment on the allergenicity of BSA. It was hypothesized that the altered structure of the allergens induced by UHP would have less available to antibody receptors. The objective of this study is to investigate the impact of UHP and different temperatures on the allergenicity of BSA. And the structural properties of BSA including free sulfhydryl content, surface hydrophobicity, extrinsic emission fluorescence spectra and secondary structure were determined. The findings may have important implications both for allergy sufferers and for the food processing community.

\section{Materials and Methods}

\section{Antigen and antibodies}

BSA and goat anti-mouse IgG conjugated with Horseradish Peroxidase (HRP) were purchased from Sigma Chemical Co. (St Louis, MO, USA). Anti-BSA mouse monoclonal-IgG was provided by National Center of Meat Quality and Safety Control (Nanjing, China).

\section{UHP treatment}

A high-pressure chamber (model S-FL-850-9-W; maximum pressure $900 \mathrm{MPa}$; Stansted Fluid Power, Stansted, UK) with a volume of $300 \mathrm{ml}$ (37 $\mathrm{mm}$ in diameter and $300 \mathrm{~mm}$ in height). The temperature of the pressure vessel was controlled via circulating water in a cooling jacket. Prior to pressure processing, BSA solutions were vacuum-conditioned in polyethylene bags. Water was used as the pressure-transmitting medium, and its temperature was separately stabilized at the required temperature $\left(25,40\right.$, and $\left.55^{\circ} \mathrm{C}\right)$ during pressure processing. BSA was dissolved in $20 \mathrm{mM}$ Tris- $\mathrm{HCl}(\mathrm{pH} 7.0)$ and was $5 \%(\mathrm{w} / \mathrm{v})$ in the polyethylene bags. These were pressurized to 100,300 , and $500 \mathrm{MPa}$ for $10 \mathrm{~min}$. After UHP treatment, the BSA solution was removed from the vessel and immediately cooled in an ice bath. Unpressurised samples served as the experimental control group.

\section{Competitive indirect-enzyme linked immunosorbent analysis (CI-ELISA)}

Each well was coated with $100 \mu \mathrm{L}$ of $0.25 \mu \mathrm{g} \cdot \mathrm{ml}^{-1}$ of BSA solution in a $0.2 \mathrm{M}$ bicarbonate buffer $(\mathrm{pH} 9.6)$ at $4^{\circ} \mathrm{C}$, overnight. The well was then blocked with $1 \%$ gelatin in 0.01

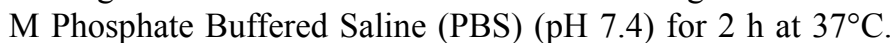
Next, $50 \mu \mathrm{L}$ of diluted anti-BSA mouse monoclonal-IgG $(1: 32000)$ in $0.01 \mathrm{M}$ PBS and $50 \mu \mathrm{L}$ of UHP-treated BSA solution (50 ng. $\mathrm{ml}^{-1}$ ) were added into each well followed by incubation for $2 \mathrm{~h}$ at $37^{\circ} \mathrm{C}$. Then, $100 \mu \mathrm{L}$ of goat anti-mouse IgG conjugated with HRP (1:10000) was added into the well followed by $2 \mathrm{~h}$ of incubation at $37^{\circ} \mathrm{C}$. Next, $100 \mu \mathrm{L}$ of freshly prepared 3, 3', 5, 5'-Tetramethylbenzidine (TMB) substrate was added to each well and reacted for $15 \mathrm{~min}$ at $37^{\circ} \mathrm{C}$ in the dark. The reaction was stopped with $50 \mu \mathrm{L}$ of $2 \mathrm{M} \mathrm{H}_{2} \mathrm{SO}_{4}$. Absorbance was measured at $450 \mathrm{~nm}$ using a microplate reader (iMark, Bio-Rad, Hercules, CA, USA). After incubation, the wells were washed three times with $0.01 \mathrm{M}$ PBS containing $0.1 \%(\mathrm{w} / \mathrm{v})$ Tween 20 . All experiments were performed in at least triplicate. The percent inhibition of each test sample was determined using the mean of the experimental wells versus the mean of the control wells using the following formula:

Inhibition percent $=\left(1-\frac{O D(\text { test sample })-O D(\text { blank })}{O D(\text { control })-O D(\text { blank })}\right)$ $\times 100 \%$

\section{(1) Determination of free sulfhydryl (SH) content}

Determination of SH used a modified Ellman's method and 5, 5'-dithiobis-2-nitrobenzoic acid (DTNB) [15]. The samples were diluted with $20 \mathrm{mM}$ Tris-HCl buffer $(\mathrm{pH} 7.0)$ to reach 2.5 mg.ml $\mathrm{m}^{-1}$ of BSA. For the assay, $40 \mu \mathrm{L}$ of $10 \mathrm{mM} \mathrm{DTNB}$ solution (in $0.09 \mathrm{M}$ Gly, 0.004 M EDTA, $0.086 \mathrm{M}$ Tris- $\mathrm{HCl}$ buffer, $\mathrm{pH} 8.0$ ) was added into $4 \mathrm{ml}$ of the sample and reacted for $5 \mathrm{~min}$ at $25^{\circ} \mathrm{C}$. The absorbance of the mixture was measured at $412 \mathrm{~nm}$ using a microplate reader (SpectraMax M2, Molecular Devices Limited, USA) using the buffer as the blank. The $\mathrm{SH}$ content was determined by dividing the absorbance by the molar extinction coefficient of 13,600. Each sample was measured in triplicate.

\section{Surface hydrophobicity $\left(H_{0}\right)$ determination}

The $\mathrm{H}_{0}$ of BSA was determined according to the method of Wang et al. [16], using 1-anilinonaphthalene-8-sulphonic acid (ANS) as the fluorescence probe. Protein dispersions were diluted $(0.005-0.2 \% \mathrm{w} / \mathrm{v})$ in $20 \mathrm{mM}$ Tris- $\mathrm{HCl}$ buffer $(\mathrm{pH} 7.0)$. Then, aliquots $(20 \mu \mathrm{L})$ of ANS $(8.0 \mathrm{mM}$ in the same buffer) were added to $4 \mathrm{ml}$ of sample. Fluorescence intensity was measured with a microplate reader (SpectraMax M2, Molecular Devices Limited, USA) at wavelengths of $390 \mathrm{~nm}$ (excitation) and $470 \mathrm{~nm}$ (emission). The initial slope of the fluorescence intensity versus protein concentration was used as an index of $\mathrm{H}_{0}$. Measurements were performed in triplicate. 


\section{Extrinsic emission fluorescence spectroscopy}

The extrinsic emission fluorescence spectra of BSA were determined according to Wang et al. [16], using 1anilinonaphthalene-8-sulphonic acid (ANS) as the fluorescence probe in a microplate reader (SpectraMax M2, Molecular Devices Limited, USA). Protein dispersions (0.2 mg. $\left.\mathrm{ml}^{-1}\right)$ were prepared in $20 \mathrm{mM}$ Tris- $\mathrm{HCl}(\mathrm{pH}$ 7.0). The samples were excited at $390 \mathrm{~nm}$, and emission spectra were recorded from 420 to $650 \mathrm{~nm}$ at a constant slit of $10 \mathrm{~nm}$ for both excitation and emission. Measurements were performed in triplicate.

\section{Circular dichroism (CD) spectra determination}

Far-UV CD spectra were acquired using a Chirascan spectrophotometer (Applied Photophysics Ltd, Surrey, UK) at room temperature $\left(20 \pm 1^{\circ} \mathrm{C}\right)$ under a constant flow of nitrogen gas. The $0.5 \mathrm{ml}$ of $0.05 \mathrm{mg} \cdot \mathrm{ml}^{-1} \mathrm{UHP}$-treated BSA or native BSA in $20 \mathrm{mM}$ Tris- $\mathrm{HCl}(\mathrm{pH} 7.0)$ was heated to room temperature prior to analysis. Each sample was scanned from 180 to $260 \mathrm{~nm}$. The CD spectrum was obtained as the average of three scans with the $20 \mathrm{mM}$ Tris- $\mathrm{HCl}$ background subtracted. Protein secondary structure of the CD spectra (190-260 nm) was analysed by using CDNN 4.1. All measurements were performed in triplicate.

\section{Statistical analysis}

All experiments were performed in triplicate, and data were evaluated with a one-way Analysis of Variance (ANOVA) using SPSS Version 9.0 program (SPSS, Chicago, IL, USA). Statistical differences with P-values under 0.05 were considered to be significant.

\section{Results and Discussion}

\section{Effect of UHP and heat treatment on the allergenicity of BSA}

Table 1 shows the effects of UHP and temperature on the allergenicity of BSA. The UHP treatment at various temperatures reduced allergenicity of UHP-treated BSA relative to the control sample. At $100 \mathrm{MPa}$ and $25^{\circ} \mathrm{C}$, no significant inhibition effect was observed. The $500 \mathrm{MPa}$ and $55^{\circ} \mathrm{C}$, however, gave the lowest inhibition of 17.53 . The inhibition of $500 \mathrm{MPa}$ and $55^{\circ} \mathrm{C}$ was $1 / 6$ of the control.

The CI-ELISA assessed the immunochemical reactivity in untreated and UHP-treated BSA. The data indicated that UHP combined with heat treatment led to a greater reduction in allergenicity of BSA. Han et al. [17] suggested that high pressure treatments $(200 \mathrm{MPa}-600 \mathrm{MPa})$ or the treatment on BGG do not show any significant changes in the allergenicity of BGG. The results might suggest BGG is heat and high pressure resistant which is different with BSA. BSA is more heat -sensitive than BGG [18]. So the treatment of HHP combined with moderate temperature on BSA gave a better allergenicity reduce as our results showed.
The decreased allergenicity of BSA might be attributed to protein conformation changes caused by high pressure and moderate temperature. It is known that UHP can induce structural unfolding, precipitation, protein denaturation, and even dissociation of some proteins into subunits. Conformational changes such as protein refolding or reaggregation may actually hide some conformational epitopes or IgE binding sites so that some allergen activities could be minimized [19].

A similar phenomenon has been reported by Nogami et al. [20] who showed that the high pressure treatment of BSA at 300-600 MPa could efficiently reduce histamine release from cells. This indicated that pressure could reduce the allergenicity of BSA-containing foods.

Table 1. Effects of UHP and heat treatment on BSA allergenicity (SD, $n=3)$.

\begin{tabular}{llll}
\hline \multicolumn{2}{l}{ Allergenicity } \\
\hline Treatment & $\mathbf{2 5 ^ { \circ } \mathbf { C }}$ & $\mathbf{4 0 ^ { \circ } \mathbf { C }}$ & $\mathbf{5 5 ^ { \circ } \mathbf { C }}$ \\
\hline Control & $100.00 \pm 0.01^{\mathrm{a}}$ & $95.42 \pm 0.89^{\mathrm{a}}$ & $90.11 \pm 0.72^{\mathrm{a}}$ \\
\hline $100 \mathrm{MPa}$ & $97.14 \pm 0.03^{\mathrm{a}}$ & $92.55 \pm 0.97^{\mathrm{b}}$ & $80.21 \pm 1.49^{\mathrm{c}}$ \\
\hline $300 \mathrm{MPa}$ & $90.71 \pm 0.05^{\mathrm{b}}$ & $75.78 \pm 0.67^{\mathrm{d}}$ & $42.42 \pm 1.46^{\mathrm{e}}$ \\
\hline $500 \mathrm{MPa}$ & $83.37 \pm 0.09^{\mathrm{c}}$ & $51.21 \pm 1.81^{\mathrm{f}}$ & $17.53 \pm 2.08^{\mathrm{g}}$ \\
\hline
\end{tabular}

Means with different letters are significantly different $(P<0.05)$. The pressure of the control is $0.1 \mathrm{MPa}$.

\section{Ultra high pressure and heat treatment on tertiary structure of BSA}

The free SH content of BSA samples was significantly influenced by UHP treatment pressure and temperature (Table 2). From $25-40^{\circ} \mathrm{C}$, the free $\mathrm{SH}$ content of BSA first increased and then decreased with pressure increases; $100 \mathrm{MPa}$ produced the highest increase, which was $4.82 \mu \mathrm{mol} / \mathrm{g}$ protein. However, as the temperature increased to $55^{\circ} \mathrm{C}$, the free $\mathrm{SH}$ content significantly $(\mathrm{P}<0.05)$ decreased to. At the same pressure, the free $\mathrm{SH}$ content in BSA significantly $(\mathrm{P}<0.05)$ decreased as the temperature was raised from $25^{\circ} \mathrm{C}$ to $55^{\circ} \mathrm{C}$ (Table 2).

The use of $100 \mathrm{MPa}$ and $25^{\circ} \mathrm{C}$ to $40^{\circ} \mathrm{C}$ heating offered the highest free $\mathrm{SH}$ values. Similar results were reported by Wei et al. [21] who found that the value of SH in egg yolk increased and then decreased with the highest values at $300 \mathrm{MPa}$. There are 17 disulfide bonds and a free-SH group in BSA [22]. The increase of $\mathrm{SH}$ content might suggest that a disruption of the disulfide bond within the protein. Meanwhile, unfolding the protein could expose the sulfhydryl groups buried in the interior of the protein, leading to an increase in the free $\mathrm{SH}$ content $[23,24]$. At this pressure, the free SH groups are stable with relatively little aggregation. At higher pressure and temperatures, hydrophobic interactions or sulfhydryl-disulfide exchange led to the aggregation/reaggregation of unfolded proteins [20]. 
However, the impact of modulating disulfide bonds is critical [22]. Restani et al. [22] showed that conservation of disulfide bridges is a critical factor in maintaining BSA antigenicity. These loops are critical in the maintenance of the conformational epitopes of BSA. Therefore, UHP affects the free $\mathrm{SH}$ content and interferes with the structure of the BSA epitopes to reduce allergicity [25].

Table 2. Effects of UHP and heat treatment on free sulfhydryl content of BSA (Treatment time is fixed at $10 \mathrm{~min}$ ).

\begin{tabular}{llll}
\hline Treatment & \multicolumn{3}{l}{ Free sulfhydryl content of BSA ( $\boldsymbol{\mu m o l} / \mathrm{g}$ protein) } \\
\cline { 2 - 4 } & $\mathbf{2 5 ^ { \circ } \mathbf { C }}$ & $\mathbf{4 0} \mathrm{C}$ & $\mathbf{5 5 ^ { \circ } \mathbf { C }}$ \\
\hline Control & $3.32 \pm 0.05^{\mathrm{a}}$ & $3.95 \pm 0.09^{\mathrm{a}}$ & $3.34 \pm 0.05^{\mathrm{a}}$ \\
\hline $100 \mathrm{MPa}$ & $4.82 \pm 0.03^{\mathrm{e}}$ & $4.14 \pm 0.03^{\mathrm{b}}$ & $3.16 \pm 0.02^{\mathrm{d}}$ \\
\hline $300 \mathrm{MPa}$ & $4.22 \pm 0.06^{\mathrm{b}}$ & $3.39 \pm 0.05^{\mathrm{c}}$ & $2.60 \pm 0.03^{\mathrm{f}}$ \\
\hline $500 \mathrm{MPa}$ & $3.23 \pm 0.06^{\mathrm{d}}$ & $2.67 \pm 0.02^{\mathrm{f}}$ & $2.18 \pm 0.04^{\mathrm{g}}$ \\
\hline
\end{tabular}

Means with different letters are significantly different $(P<0.05)$. The pressure of the control is $0.1 \mathrm{M} \mathrm{Pa}$.

The BSA H0 data is shown in Table 3 . From $25^{\circ} \mathrm{C}$ to $40^{\circ} \mathrm{C}$, the $\mathrm{H}_{0}$ of BSA increased greatly $(\mathrm{P}<0.05)$ at $100 \mathrm{MPa}$ relative to control. It decreased from 300 to $500 \mathrm{MPa}$. When the temperature was $55^{\circ} \mathrm{C}$, however, the $\mathrm{H}_{0}$ decreased from 69.79 to 19.68 at the pressure range of 100 to $500 \mathrm{MPa}$.

The $\mathrm{H}_{0}$ data reflect differences in protein aggregation or refolding. UHP may cause the hydrophobic groups that were buried in the hydrophobic interior to become exposed to the solvent. This will disrupt the hydrogen bonds that modulate protein folding. Thus, the $\mathrm{H}_{0}$ of BSA increased from $25-40^{\circ} \mathrm{C}$ at $100 \mathrm{MPa}$ relative to controls [12]. The UHP (300 and 500 $\mathrm{MPa})$ and a higher temperature $\left(55^{\circ} \mathrm{C}\right)$, however; decreased the $\mathrm{H}_{0}$. The UHP and heating may cause association of subunits and disrupt the tertiary structure. It may result in aggregation. Thus, the decrease in surface hydrophobicity of BSA after pressure and moderate heating was probably related to the formation of soluble and insoluble aggregates of subunits. Thus, it is possible that the treatments lead to intense proteinprotein interactions via the formation of complex aggregates caused by reduced exposure of the hydrophobic groups $[12,21]$.

Table 3. Effects of UHP and heat treatment on the relative surface hydrophobicity of BSA.

\begin{tabular}{llll}
\hline Treatment & \multicolumn{2}{l}{ Relative surface hydrophobicity $\left(\mathbf{H}_{0}\right)$} \\
\cline { 2 - 4 } & $\mathbf{2 5 ^ { \circ } \mathbf { C }}$ & $\mathbf{4 0 ^ { \circ } \mathbf { C }}$ & $\mathbf{5 5 ^ { \circ } \mathbf { C }}$ \\
\hline Control & $100.00 \pm 1.75^{\mathrm{b}}$ & $98.81 \pm 1.29^{\mathrm{a}}$ & $96.53 \pm 0.22^{\mathrm{a}}$ \\
\hline $100 \mathrm{MPa}$ & $109.30 \pm 1.20^{\mathrm{a}}$ & $108.30 \pm 1.50^{\mathrm{c}}$ & $69.79 \pm 2.58^{\mathrm{d}}$ \\
\hline $300 \mathrm{MPa}$ & $95.72 \pm 1.21^{\mathrm{a}}$ & $58.96 \pm 0.78^{\mathrm{e}}$ & $35.19 \pm 1.10^{\mathrm{g}}$ \\
\hline $500 \mathrm{MPa}$ & $71.19 \pm 2.06^{\mathrm{d}}$ & $20.66 \pm 0.66^{\mathrm{f}}$ & $19.68 \pm 0.40^{\mathrm{g}}$ \\
\hline
\end{tabular}

Means with different letters are significantly different $(P<0.05)$. The pressure of the control is $0.1 \mathrm{MPa}$.

Table 4 shows the fluorescence intensity of ANS binding to BSA treated at various pressures and temperatures. The fluorescence emission intensity indicated a gradual decrease at 100, 300, and $500 \mathrm{MPa}$. The fluorescence intensity which was positively correlated with surface hydrophobicity was higher than the control induced by a pressure of $100 \mathrm{MPa}$ from $25-40^{\circ} \mathrm{C}$. When the temperature increased to $55^{\circ} \mathrm{C}$, the value of fluorescence intensity decreased to a minimum compared with the others.

ANS is fluorescent dye that binds to nonpolar regions of proteins by non-covalent bonds. It offers sensitive detection of structural changes and aggregated protein [26]. These findings agree with Yan et al. [21], who found that a pressure of 100-500 MPa significantly decreased $\mathrm{H}_{0} ; 50^{\circ} \mathrm{C}$ treatment affected the weak binding site close to the C-terminal. Therefore, the $\mathrm{H}_{0}$ decreased relative to the UHP-treated samples [26,27].

UHP (100 MPa at $25-40^{\circ} \mathrm{C}$ ) can cause the hydrophobic groups buried within the hydrophobic interior to come to the exterior. When treated at a higher pressure and temperature, the fluorescence intensity significantly decreased. A similar phenomenon was reported by Nogami et al. [20], who confirmed that $100 \mathrm{MPa}$ for $10 \mathrm{~min}$ at $15^{\circ} \mathrm{C}$ markedly decreased the fluorescence intensity of BSA.

The decrease in fluorescence indicated a loosening of the protein conformation, which reduced ANS binding and offered increased exposure of the hydrophobic groups [28]. At 500 $\mathrm{MPa}$ at $55^{\circ} \mathrm{C}$, the fluorescence data indicated that the binding regions of BSA-ANS became more hydrophilic. Thus, the ANS separated from the binding motif-this decreased the fluorescence. On the other hand, Takeda et al. [27] reported that ANS binds to BSA in up to five different binding sites. Thus, heating could disturb the affinity of the weak sites.

Table 4. Effects of UHP and heat treatment on the fluorescence emission intensity of BSA.

\begin{tabular}{llll}
\hline Treatment & \multicolumn{2}{l}{ Emission intensity } \\
\cline { 2 - 4 } & $\mathbf{2 5 ^ { \circ } \mathbf { C }}$ & $\mathbf{4 0} \mathbf{C}$ & $\mathbf{5 5 ^ { \circ } \mathbf { C }}$ \\
\hline Control & 2239.92 & 2029.38 & 1921.43 \\
\hline $100 \mathrm{MPa}$ & 4829.98 & 2879.55 & 1822.54 \\
\hline $300 \mathrm{MPa}$ & 3692.96 & 1801.50 & 1343.37 \\
\hline $500 \mathrm{MPa}$ & 2166.12 & 1414.43 & 832.13 \\
\hline
\end{tabular}

\section{Effects of ultra-high pressure and heat treatment on secondary structure of BSA}

Table 5 shows far-UV CD data. The result indicated a decrease in the $\alpha$-helix and an increase in the $\beta$-sheet. Meanwhile, the zero-crossing points shifted to the left. The CD spectrum of native BSA is characteristic of $67.9 \% \alpha$-helix, $3.8 \% \beta$-sheet, 
$11.9 \% \quad \beta$-turn, and $16.5 \%$ random coil. The change in secondary structure of BSA after pressurization and heat treatments are shown in Table 5. The temperature combined and UHP significantly decreased the $\alpha$-helix and significantly increased the $\beta$-sheets, $\beta$-turns and random coils. The helical proportion sharply decreased to $37.8 \%$ upon raising the temperature to $55^{\circ} \mathrm{C}$.

The secondary structures include $\alpha$-helix, $\beta$-sheet, $\beta$-turn and random coil. The literature suggests that higher temperatures and pressures will seriously denature BSA. In our study, the greatest change was observed for the sample treated for $10 \mathrm{~min}$ at $500 \mathrm{MPa}$ and $55^{\circ} \mathrm{C}$. Yamamoto et al. [1] treated BSA with $600 \mathrm{MPa}$ at $5-7^{\circ} \mathrm{C}$ for $5 \mathrm{~min}$. They showed only a slight increase in the $\beta$-structure after treatment with no significant change in the secondary structure. They concluded that changing the secondary structure did not reduce allergenicity. In contrast, our results showed that the high pressure and moderate heat treatments induced significant alterations in secondary structures. These alterations of secondary structures suggested that the allergenicity of BSA might be associated with the secondary structure.

Barbara et al. [29] suggested that serum albumin antigenicity was only partially correlated with its native three-dimensional structure. BSA is a heart-shaped protein composed of three structurally similar helical domains termed I-III. Many of the BSA epitopes are located on the $\alpha$-helices of domain II [30]. Thus, the reduced allergenicity might be that the high temperature and pressure destroyed some secondary structures of BSA.

Table 5. Effects of UHP and heat treatment on secondary structure composition of BSA (SD, $n=3)$.

\begin{tabular}{|c|c|c|c|c|}
\hline Treatment & a-helix (\%) & $\beta$-sheet (\%) & $\beta$-turn (\%) & Random coil (\%) \\
\hline Control & $67.9 \pm 1.1^{\mathrm{a}}$ & $3.8 \pm 0.3^{d}$ & $11.9 \pm 0.1^{g}$ & $16.5 \pm 0.7^{\mathrm{e}}$ \\
\hline $100 \mathrm{MPa}, 25^{\circ} \mathrm{C}$ & $64.2 \pm 0.5^{\mathrm{b}}$ & $4.4 \pm 0.2^{\mathrm{d}}$ & $12.4 \pm 0.1^{f}$ & $19.0 \pm 0.3^{d}$ \\
\hline $300 \mathrm{MPa}, 25^{\circ} \mathrm{C}$ & $54.2 \pm 0.9^{c}$ & $6.5 \pm 0.4^{\mathrm{c}}$ & $14.0 \pm 0.2^{\mathrm{de}}$ & $25.2 \pm 0.4^{c}$ \\
\hline $500 \mathrm{MPa}, 25^{\circ} \mathrm{C}$ & $45.8 \pm 1.5^{\mathrm{d}}$ & $9.5 \pm 0.7^{b}$ & $15.4 \pm 0.2^{b c}$ & $29.4 \pm 0.6^{b}$ \\
\hline Control & $63.2 \pm 0.2^{\mathrm{a}}$ & $4.1 \pm 0.3^{d}$ & $12.4 \pm 0.1^{g}$ & $20.1 \pm 0.9^{e}$ \\
\hline $100 \mathrm{MPa}, 40^{\circ} \mathrm{C}$ & $62.5 \pm 1.7^{\mathrm{b}}$ & $4.7 \pm 0.4^{d}$ & $12.6 \pm 0.2^{f}$ & $20.2 \pm 1.1^{d}$ \\
\hline $300 \mathrm{MPa}, 40^{\circ} \mathrm{C}$ & $53.7 \pm 0.7^{c}$ & $6.7 \pm 0.2^{\mathrm{c}}$ & $14.2 \pm 0.2^{\mathrm{d}}$ & $25.5 \pm 0.4^{\mathrm{c}}$ \\
\hline $500 \mathrm{MPa}, 40^{\circ} \mathrm{C}$ & $44.9 \pm 0.8^{d}$ & $10.0 \pm 0.4^{b}$ & $15.6 \pm 0.2^{\mathrm{b}}$ & $29.5 \pm 0.3^{b}$ \\
\hline Control & $60.5 \pm 0.9^{a}$ & $5.2 \pm 0.3^{d}$ & $13.1 \pm 1.9 \mathrm{~g}$ & $21.2 \pm 0.3^{\mathrm{e}}$ \\
\hline $100 \mathrm{MPa}, 55^{\circ} \mathrm{C}$ & $56.0 \pm 0.4^{c}$ & $6.0 \pm 0.2^{c}$ & $13.7 \pm 0.1^{\mathrm{e}}$ & $24.2 \pm 0.1^{c}$ \\
\hline $300 \mathrm{MPa}, 55^{\circ} \mathrm{C}$ & $47.4 \pm 0.3^{d}$ & $9.4 \pm 0.8^{b}$ & $15.0 \pm 0.2^{c}$ & $28.3 \pm 0.8^{b}$ \\
\hline $500 \mathrm{MPa}, 55^{\circ} \mathrm{C}$ & $37.8 \pm 0.3^{e}$ & $14.0 \pm 0.4^{\mathrm{a}}$ & $16.6 \pm 0.1^{a}$ & $31.6 \pm 0.2^{a}$ \\
\hline
\end{tabular}

Different superscript letters in the column indicated significant different pressure and temperature treatment groups $(\mathrm{P}<0.05)$. The pressure of the control is $0.1 \mathrm{MPa}$.

\section{Discussion and Conclusion}

Pressure and heat treatment affect the structure of BSAespecially the tertiary structure. The UHP and heat result in unfolding, aggregation and conformational changes. The free $\mathrm{SH}$ content and the $\mathrm{H}_{0}$ increased and then decreased sharply as a function of pressure $(300-500 \mathrm{MPa})$ at $25-40^{\circ} \mathrm{C}$ which indicated that the conformational changes are due to protein unfolding from broken disulfide bonds. At $55^{\circ} \mathrm{C}$, the decreasing value of $\mathrm{SH}$ and $\mathrm{H}_{0}$ indicates an impact on sulfhydryl-disulfide exchange. In turn, the reaction of hydrophobic groups increased. Additionally, UHP resulted in a significant decrease in the $\alpha$-helix, while there was a significant increase in the $\beta$-sheet, $\beta$-turn and random coil. The treatment could destroy some secondary structures of BSA. This combination of UHP and moderate heat treatments might not only prevent beef and milk allergies, but could also be applied to produce hypoallergenic beef and milk.

\section{Contribution of Authors}

Yepei Zhu and Wei Wang have equal contribution to this work.

\section{Conflict of Interest}

No conflict of interest associated with this work.

\section{Acknowledgments}

This work was supported by Natural Science Foundation of Jiangsu Province (BK20140722) and the National Natural Science Foundation of the People's Republic of China (31501395).

\section{References}

1. Yamamoto S, Mikami N, Matsuno M. Effects of a highpressure treatment on bovine gamma globulin and its 
reduction in allergenicity. Biosci Biotechnol Biochem 2010; 74: 525-530.

2. Fiocchi A, Restani P, Riva E. Beef allergy in children. Nutrition 2000; 16: 454-457.

3. Jansen JJ, Kardinaal AF, Huijbers G. Prevalence of food allergy and intolerance in the adult Dutch population. J Allergy Clin Immunol 1994; 93: 446-456.

4. Klug C, Focke M, Hemmer W. Identification and characterization of meat allergens for improved diagnosis of meat allergy. Clin Transl Allergy 2013; 3: 1 .

5. Kim KBWR, Lee SY. Effect of heat and autoclave on allergenicity of porcine serum albumin. Food Sci Biotechnol 2011; 20: 455-459.

6. Kim KBWR, Kim SJ, Lee SY. Changes in allergenicity of porcine serum albumin by microwave, sonication, and high hydrostatic pressure. Korean J Food Sci Anim Resourc 2008; 28: 499-504.

7. Restani P, Fiocchi A, Beretta B. Effects of structure modifications on IgE binding properties of serum albumins. Int Arch Allergy Immunol 1998; 117: 113-119.

8. Majorek KA, Porebski PJ, Dayal A. Structural and immunologic characterization of bovine, horse, and rabbit serum albumins. Mol Immunol 2012; 52: 174-182.

9. Kleber N, Maier S, Hinrichs J. Antigenic response of bovine $\beta$-lactoglobulin influenced by ultra-high pressure treatment and temperature. Innov Food Sci Emerg Technol 2007; 8: 39-45.

10. Nishio T, Iida S. Mutants having a low content of $16-\mathrm{kDa}$ allergenic protein in rice (Oryza sativa L.). Theor Appl Gene 1993; 86: 317-321.

11. Maria SD, Ferrari G, Maresca P. Rheological characterization bovine serum albumin gels induced by high hydrostatic pressure. Food Nutr Sci 2015; 6: 770-779.

12. He R, He HY, Chao D. Effects of high pressure and heat treatments on physicochemical and gelation properties of rapeseed protein isolate. Food Bioproc Technol 2014; 7 : 1344-1353.

13. Johnson PE, Iesel VDP, Ana B. High pressure, thermal and pulsed electric-field-induced structural changes in selected food allergens. Mol Nutr Food Res 2010; 54: 1701-1710.

14. Hajos G, Polgar M, Farkas J. High-pressure effects on IgE immunoreactivity of proteins in a sausage batter. Innovative Food Sci Emerg Technol 2004; 5: 443-449.

15. Ellman GL. Tissue sulfhydryl groups. Arch Biochem Biophys 1959; 82: 70-77.

16. Wang XS, Tang CH, Li BS. Effects of high-pressure treatment on some physicochemical and functional properties of soy protein isolates. Food Hydrocolloids 2008; 22: 560-567.

17. Han GD, Matsuno M, Ikeuchi Y. Effects of heat and highpressure treatments on antigenicity of beef extract. Biosci Biotechnol Biochem 2002; 66: 202-205.
18. Sun XD, Holley RA. High hydrostatic pressure effects on the texture of meat and meat products. J Food Sci 2010; 75: 17-23.

19. Han GD, Fan JP, Suzuki A. Changes of SDS-PAGE pattern and allergenicity of BSA and BGG in beef extract treated with heat and high pressure. J Korean Soc Food Sci Nutr 2006; 35: 35.

20. Nogami N, Matsuno M, Hara T. Elimination of the allergenicity of food protein by high pressure. Rev High Press Sci Technol 2006; 16: 11-16.

21. Yan W, Qiao L, Gu X. Effect of high pressure treatment on the physicochemical and functional properties of egg yolk. Eur Food Res Technol 2010; 231: 371-377.

22. Restani P, Ballabio C, Cattaneo A. Characterization of bovine serum albumin epitopes and their role in allergic reactions. Allergy 2004; 59: 21-24.

23. Chen X, Chen CG, Zhou YZ. Effects of high pressure processing on the thermal gelling properties of chicken breast myosin containing $\beta$-carrageenan. Food Hydrocolloids 2014; 40: 262-272.

24. Chen X, Li PJ, Nishiumi T. Effects of high-pressure processing on the cooking loss and gel strength of chicken breast actomyosin containing sodium alginate. Food Bioproc Technol 2014; 7: 3608-3617.

25. Shriver SK, Yang WW. Thermal and nonthermal methods for food allergen control. Food Eng Rev 2011; 3: 26-43.

26. Togashi DM, Ryder AG. A fluorescence analysis of ANS bound to bovine serum albumin: Binding properties revisited by using energy transfer. J Fluores 2008; 18: 519-526.

27. Takeda K, Wada A, Yamamoto. Conformational change of bovine serum albumin by heat treatment. J Prot Chem 1989; 8: 653-659.

28. Celej MS, Montich GG, Fidelio GD. Protein stability induced by ligand binding correlates with changes in protein flexibility. Prot Sci Publ Prot Soc 2003; 12: 1496-1506.

29. Beretta B, Conti A, Fiocchi A. Antigenic determinants of bovine serum albumin. Int Arch Allergy Immunol 2001; 126: 188-195.

30. Majorek KA, Porebski PJ, Dayal A. Structural and immunologic characterization of bovine, horse, and rabbit serum albumins. Mol Immunol 2012; 52: 174-182.

\section{*Correspondence to}

Wei Wang

College of Food Science and Technology

Nanjing Agricultural University

PR China 